\title{
Iconoclastic ethics
}

\author{
Douglas Black Emeritus Professor of Medicine, Manchester University
}

\section{Author's abstract}

Arguments are advanced, on a pragmatic basis, for preferring $a$ 'situational' approach to medical ethical problems, rather than an approach based on any one of the dogmatic formulations on offer. The consequences of such a preference are exemplified in relation to confidentiality; and in relation to the ethical dilemmas which surround the beginning and the end of terrestrial human life.

Quite often these days, I have to begin a lecture by explaining the title which I have given it, for I am running out of suitable self-explanatory titles for what I want to say. My theme in this talk is to express an element of controlled scepticism about the fruits of the labour of those who devise codes of medical ethics; and to illustrate some of the pitfalls which may open when such codes are interpreted rigidly, and not as guidelines. Perhaps I can begin by making it quite clear that I have both sympathy and admiration for those who do set about the task of giving sensible guidance to practitioners of their professions; this sympathy is extended both to members of the General Medical Council, on whom is laid the statutory duty of providing such guidance; and to those who volunteer to do so, such as members of the Ethical Committee of the British Medical Association.

Against this background of genuine sympathy for the successors of Hammurabi and Hippocrates, what genuine motives can I have for being sceptical about the end-products? I can perhaps distinguish three - the lack of any consensus on an absolute basis for ethics; positive sympathy with 'situation ethics'; and a severe touchstone for judging ethical statements, to wit, do they benefit the patient?

As a son of the Manse, my own wASPish provenance is impeccable; but in later life it has not escaped my observation that the beliefs to which such a background predisposes are not universally shared. I suspect further that the seamless robe of mediaeval Christianity, from which such universal systems as those of Aquinas could spring, was held together more by the rigour of the sanctions for conformity than by

\section{Key words}

Medical ethics; situation ethics. any true commonalty of belief. This insight, even true, gives me no particular pleasure - at its best, the Christian religion has transcended Lucretiab invective. However, in the real world we have to try to help people of different races and religions; and I have long held the view that we must give a high, even if nof an absolute priority, to the consequences of whatevep system of belief, or even unbelief, our patients may hold. High, because it seems to me unfair to take advantage of the testing time of an illness to questior by word or deed a system by which the patient has learned to live and ultimately to die. But not absolute since our actions must ultimately be constrained by ou own consciences - for example, I would not myself abeep suicide at the request of a patient, even though for dying man I would be willing to prescribe high doseso analgesics with depressant side-effects.

Even if we had consensus on an ethical system which gave a clear guiding light, it seems to me tha codification is likely to break down on the truism tha? 'every case has to be considered on its merits'. This position, sometimes crystallised in the phrase 'situation ethics' has, I think, always informed m practice; but it was made more explicit for me a few years ago, when I took part in an exercise on Granadæ. television in which a panel of about 15 healt professionals and lay people were asked to give views. on hypothetical situations, propounded by a barrister in this instance Paul Sieghart. The underlying ethica question in this particular programme was whetheg disclosures should ever be made voluntarily to the police; and the particular situation described was that of a woman who told her doctor that she had swallowe a diamond before immigration, and it had not appeare $\$ 1$ - the majority of the panel felt that this should not be reported. But when the dilemma was made more acute్ల by substituting a bag of heroin for the diamond, opinop swung the other way, though one or two doctors said that even then they would not involve the police. I described my own sticking-point as somewhere between the diamond and the heroin. The lesson that $I_{0}$ extracted was that the reasonable principle, ' $n \bar{\Phi}$ disclosure to the police without the consent of the patient', should on occasion be breached.

My third general reason for scepticism about at anf rate some codifications of medical ethics stems fronf 
the belief, which I expressed and even validated at some length in my Harveian Oration (1), that medicine is primarily for the individual patient, even if it may also benefit populations, or society, or the biosphere, or contribute to the advance of knowledge. In particular, it is the duty of a doctor, as a professional man, to put the interests of his patient even above his own. Now, although I have had much converse with sociologists, I remain of the old-fashioned belief that it is in the interests of patients that the medical profession should be both respectable and respected; so I welcome in general terms the provisions which control advertisement, fee-splitting, association with unqualified practitioners and the like. Nevertheless, there must be some cases in which conduct which follows from such rules may appear to be dedicated more to the preservation of professional purity than to the welfare of the patient. For example, it is beyond doubt that many patients derive considerable benefit from the ministrations of unorthodox practitioners of various types. I am no more anxious than any other doctor to encourage unorthodox practitioners; but it would seem to me to be in the interests of patients that we should at least know what is being done for them, and this we cannot directly learn without some degree of association.

For these various reasons, I do not see medical ethics as a pre-set code for blind adherence, but as a system of relationships which may require substantial modification in the light of the character of the people involved, and of the situations in which they find themselves. In my view, the paramount relationship is that between doctor and patient; but doctors also have responsibilities to relatives, to other doctors, to other workers in the health service, and to society and its agents. From the stress which I am laying on relationships, it follows that we must not only strive to act correctly, but also take pains to explain our actions to those who are materially affected by them. Trouble can arise, not only from actions which are intrinsically wrong, but from the misrepresentation of actions which are in themselves correct. Such misrepresentation may be a reaction to faulty communication by the doctor, or a sign of a faulty personal relationship between doctor and patient, although it may also stem from a prejudiced attitude on the part of the patient or his relatives.

Having enunciated my two basic beliefs - that medical ethics are relative and not absolute; and that they are concerned with a nexus of relationships - let me go on to illustrate how I see these conditions applied to particular areas, which I hope may combine perennial and topical interest.

\section{Confidentiality}

This is both a continuing concern for all health professionals, and a matter of topical interest in view of imminent legislation, both in Europe and in this country, on the protection of data held in mechanically processed systems. There is, incidentally, something of an anomaly in concern being focused on such systems more immediately than on the much larger amount of information held in manual records, which would seem on the face of it more accessible to the casual, but improper searcher. However, this may merely be an accident of timing, and the same principles of confidentiality should apply to both types of records, even though the means of ensuring good conduct will differ in detail between the two systems. Another general point which must be recognised is that information on personal health is a highly sensitive area, perhaps more so than financial information, even if possibly less so than a record of criminal activity.

It is easy to discern three reasonable and reasonably clear objectives relevant to personal health information: the subject of the information has a certain right of access to it; he would not wish it to be divulged to third parties, and both the patient and the recorder of the information are interested that it should be maximally useful. Even stated in this general form, the possibility of conflict among these three objectives can be fairly readily seen. For example, the safeguards required to restrict access by third parties are likely also to constitute at any rate a partial obstacle to access by the subject of the data; and steps taken to convert identifiable information into unidentified information will clearly be a hindrance to that part of the usefulness of data which relates to the clinical care of individuals.

Not only, however, are these three objectives to some extent mutually incompatible; each one of them in itself falls short of an absolute requirement.

There is an element of natural justice in the proposition that people should have free access to information which is being held about them on matters of health, even if this is not a right which it is customary for them to exercise (though I suspect that with the conventional hospital case notes it is not unknown for patients or relatives to have a glance at them). But it seems to me a right which should quite properly be hedged around with some limitation. To make a horrid confession, I am slightly out of tune with what has become the prevailing belief, at any rate among health sociologists, that the more patients know about their illness, the better for them. Ignorance may be, if not actually bliss, at any rate less upsetting than particular items of knowledge. To this general, if perhaps improper, concern of mine can be added more specific considerations. Medical language can easily be misunderstood by those not familiar with it (and even by some who are); knowledge of the precise nature of illness, present or past, can cause anxiety which would not be aroused by sympathetic partial disclosure; and observations on the patient's mental state and level of intelligence, while helpful on a subsequent visit to the same or another doctor, might occasion resentment if communicated to the patient. (I do not agree with the argument that observations of this type should not be recorded; but I fear that they might not be if mandatory access by patients to their records became a 
legal requirement).

It is clearly in the general interest of those on whom health information is held that the information which they have given under the seal of confidence (whether this be explicitly stated, or reasonably implied) should not be divulged. But a rigid application of this principle would effectively sterilise the information from all future use; and to a less extent the requirement of specific formal consent from a patient for any disclosure of information seems to me to be, in certain conditions, an unnecessary hindrance. When a patient is referred from a general practitioner to a consultant, or from one consultant to another, it would seem to me that the patient's agreement to be so referred also constitutes an implied consent for information about him to be transferred, and in these circumstances explicit consent is not required. Similarly, disclosures on the health of patients who have died are legitimate when they tend towards the credit of the deceased; and I share the surprise of the editor of the British Medical Fournal at his receipt of a 'warning letter' from the General Medical Council in such circumstances (2). But the situation is entirely different when the information sought is clearly going to be used to the possible detriment of the patient, in such contexts as illegal immigration, tax evasion, or the planning and committing of a crime. Some doctors would consider that the likelihood of information being used 'against a patient' constitutes an absolute bar to its disclosure, and I would agree with this in the context of immigration or tax evasion. But in the context of planning or committing crime which would be generally regarded as serious, such as rape, murder and acts of terrorism, I take a different view. When a crime has been committed, and a suspect brought to trial, a judge can require a doctor to disclose relevant information, though the judge would not do so lightly; it remains open to the doctor to refuse, providing he is willing to bear the consequences. The situation when a doctor becomes aware that a serious crime is being planned is still more difficult; I believe that in a situation such as mass terrorism, the doctor's duty to society overrides his obligation to confidentiality; and personally I would make a voluntary disclosure to police in such circumstances.

I do not consider that the restrictions currently being placed on access to records will materially impair their usefulness in a clinical context, even though they may arouse some hesitations in the transfer of information from say the medical record to the records of other health professionals who may not as yet come under ethical safeguards monitored by bodies such as the General Medical or Nursing Councils. But there is a very proper concern about the effect of new restrictions on the use of records for epidemiological and social research. The purist position is that such use can be legitimated only by obtaining the patient's specific consent - a matter of some difficulty if he happens to be dead. Personally, I would be content with the position that a patient's entry into a clinical situation creates a presumption that he would be willing for his clinica record to be used for bona fide research, at any rate søn long as any results were published in such a way tha랄. the individuals on whom they were based could not bee? identified. In the less common circumstances in which: identification of the subjects may be necessary, clearly their specific consent must then be obtained.

\section{Prevention/promotion of pregnancy}

This represents another area in which society iฆ massively confused, a confusion which is shared by the medical profession. Against a general background of the pressure of population on resources, we se $\vec{\epsilon}$ individuals whose dearest wish is to have children, and others, rather more numerous perhaps, who wisł exactly the opposite. In this dilemma, and in accord. with my general thesis, I see little help being obtained from either of the two extreme ethical positions, of which one might be stated as 'A woman's body is hero own, to do what she likes with'; and the other as 'Prevention or termination of pregnancy is a crime against God and man'.

One experience which influenced me quite strongl to my belief that medical ethics are relative and noB absolute was my membership of the General Medica Council at the time when termination of pregnancy under certain conditions changed overnight frones being a crime to being something entirely legal, under appropriate safeguards. Having seen the illness a sometimes death produced by back-street abortionisis I am in no doubt that this legislation was on balance socially desirable, even if open to abuse. But equally on medical grounds at least, effective contraception i\& much preferable to the termination of an unwanted pregnancy.

There are two topical issues, one related to termination, the other to contraception, on whic opinion legitimately differs. The age of 28 weeks was. somewhat arbitrarily set, as likely to exclude viability of the conceptus, but in the meantime the techniques for preserving the life of prematurely born infants have greatly advanced. There seem to me to be reasonable grounds for reconsidering this precise upper limit for termination: but the ground for doing so is the technically induced change in the possibility of $\rightarrow$ healthy life for a conceptus born before the 28 th week not a campaign to make abortion once again illegal of The issue relating to contraception takes us back once again to confidentiality, and to whether it is 'right' tP prescribe 'the pill' for a young girl without telling hefo parents, she having declined to do so. This is the course of action advised by the General Medical Councile provided of course that every effort has been made to persuade the girl either to tell the parents herself, or to allow the doctor to do so. That is certainly not the worst course of action, which would be to refuse to prescribo the pill, thus exposing the girl to the risks of a unwanted pregnancy. But in some instances, not oo course in all, I would myself tell the parents, telling the 
girl why I was doing so against her wishes; teenage girls are not the repositories of all wisdom, and I would not feel obliged to give their wishes total priority in this particular context.

\section{Matters of life and death}

The general position here seems to me quite plain - it is the prime task of the doctor to take part in the preservation of life and health, which precludes his participation in capitai punishment or torture. But when it comes to severely handicapped infants or the victims of painful terminal illness, I see the duty of preserving life at all costs as something less than absolute. The simplest case is where brain stem death has unequivocally taken place (3), but vital functions are being mechanically maintained - any ethical dilemmas here would be limited to those who granted unequivocal belief to the lay pundits of Panorama. Next in difficulty comes the matter of painful terminal illness in the elderly, and my personal practice was to give adequate sedation, to avoid active resuscitation measures, but not to take any active steps to hasten death, and certainly to do nothing approaching the distasteful manoeuvres of the organisation known as EXIT (now again the Voluntary Euthanasia Society). On quite different grounds, I am not enamoured of the activities of the comparable anti-abortion pressure group, LIFE, and certainly not of the encouragement which they give to informers in maternity units. The two groups, so apparently disparate, have this in common, that they pursue an aim and purpose not in itself unequivocally bad, to the exclusion of considering all the relevant particulars in individual cases. My own personal sympathies lie more with LIFE than with the Voluntary Euthanasia Society. Even if the former exalts existence to an absolute, with no sympathy for the burdens imposed by handicap; the latter, in the name of compassion, opens the door to unequivocally criminal conduct.

My final piece of iconoclasm is to stress the relative unimportance of formal ethics in actually promoting good medical practice. The word relative is significant - if I thought ethics were absolutely unimportant, I would not be wasting my time and yours in talking about them. But I do feel quite strongly that we derive our major ethical standpoints in various ways other than formal teaching: from our origins and backgrounds; from our growing acquaintance with patients; and from the perceived behaviour much more than the contrived utterances of those who make bold to teach us. The real bases of good medical practice seem to me to be human sympathy and kindness; wide knowledge and technical competence; and an element of prudence, which may be no more than common sense. Given these, the doctor does not have to spend too much time looking over his ethical shoulder. There are of course standards of conduct below which no doctor should fall, and a purpose is served by setting out with clarity these minimal standards; but they represent the baseline or floor of achievement and in no way the aim or ceiling.

This paper is based on the Sixth Curran Lecture given at St George's Hospital Medical School, 1984 April 11.

\section{References}

(1) Black D. Cui bono? British medical journal 1977; 2: 1109 1114

(2) Lock S. A question of confidence. British medical journal 1984; $1:$ 125-127.

(3) Pallis C. ABC of brain stem death. London: British medical journal, 1983.

Update

Society of Apothecaries: Diploma pass list

The following passed the final examination of the Society of Apothecaries' Diploma in the Philosophy of Medicine: Dr J F Fisher; Dr J M Heron; Dr S M Lundy; and $\mathrm{Dr} \mathrm{J}$ O'Melia (with distinction). 